\title{
A diversidade vai à creche: reflexões sobre a implementação da Lei Federal 10.639/03 na Creche do Morro da Queimada em Florianópolis
}

\author{
Paulino de Jesus Francisco Cardoso ${ }^{1}$
}

Cintia Cardoso ${ }^{2}$

Resumo: Este artigo tem por propósito problematizar e discutir as implicações da implementação da Lei Federal 10.639/03 na Creche Morro da Queimada, da Rede Municipal de Ensino de Florianópolis/SC. A partir de um levantamento dos marcos normativos da Educação Infantil e das Diretrizes Curriculares Nacionais para a Educação das Relações Étnico-Raciais e para o Ensino de História e Cultura Afro-Brasileira e Africana (BRASIL, 2005), pretendemos aprofundar nossas análises nos aspectos referentes à prática pedagógica que instigou nosso interesse pela investigação das contradições e ações experienciadas no cotidiano da unidade educativa voltado à promoção da igualdade racial. Para tanto, ancoramos nossa pesquisa em dois aspectos: branquitude normativa e descolonização dos currículos. Diante de tal complexidade, nossas ações serão voltadas para analisar a aplicação da Lei

1 Doutor em História pela Pontifícia Universidade Católica de São Paulo. Coordenador do Projeto de Extensão "Suporte às Políticas Públicas de Implementação da Lei 10.639/03 em Santa Catarina" vinculado ao Programa Memorial Antonieta de Barros, do Núcleo de Estudos Afro-Brasileiros da UDESC. Presidente da Associação Brasileira de Pesquisadores Negros - ABPN e coordenador do Núcleo de Estudos Afro-Brasileiros - NEAB/UDESC. E-mail: paulino.cardoso@gmail.com.

${ }^{2}$ Mestranda em Educação pelo Programa de Pós Graduação da Universidade Federal do Paraná- UFPR. Atualmente é pesquisadora associada ao Núcleo de Estudos AfroBrasileiros (NEAB/UDESC) e voluntária no Projeto de Extensão "Suporte às Políticas Públicas de Implementação da Lei 10.639/03 em Santa Catarina”. E-mail: cinttiacardoso@gmail.com. 
Federal 10.639/03, coadunando com as políticas de promoção da igualdade racial na Rede Municipal de educação infantil de Florianópolis/SC; pretendese verificar quais os mecanismos utilizados para a construção de uma educação voltada para promoção da igualdade racial. O presente artigo é resultado do projeto extensionista "Suporte às Políticas Públicas de Implementação da Lei Federal 10.639/03 em Santa Catarina", vinculado ao Programa Memorial Antonieta de Barros, do Núcleo de Estudos AfroBrasileiros da UDESC. Com este estudo pretendemos contribuir para superar as contradições, favorecendo o debate sobre as relações raciais e a implementação da Lei 10.639/2003 na instituição analisada, apontando caminhos para adesão coletiva da proposta e potencializando descobertas de metodologias para aplicação efetiva da Lei nas práticas pedagógicas.

Palavras-chave: Lei 10.639/03. Educação Infantil. Descolonização Curricular. Relações Étnicorraciais. Florianópolis.

\section{Introdução}

Este artigo tem por propósito problematizar e discutir as implicações da implementação da Lei Federal n. 10.639 em uma creche da Rede Municipal de Ensino de Florianópolis - SC. A partir do levantamento dos marcos normativos da Educação Infantil (BRASIL, 1995), das Diretrizes Curriculares Nacionais para a Educação das Relações Étnico-raciais e para o Ensino de História e Cultura AfroBrasileira e Africana (BRASIL, 2005) e um levantamento dos documentos oficiais da instituição estudada, pretende-se aprofundar alguns aspectos referentes à prática pedagógica que instigaram nosso interesse na investigação das contradições e ações no espaço escolar. 
Diante de tal complexidade, destacamos a importância de analisar a adoção de ações afirmativas no âmbito educacional que têm influenciado os currículos, coadunando com a compreensão das políticas de promoção da igualdade racial na rede de educação infantil de Florianópolis. Da mesma forma, refletiremos sobre os mecanismos utilizados para a construção de uma educação referente à assunção da valorização da diversidade cultural e da promoção das relações étnicorraciais.

Para além do cumprimento de dispositivos legais, que suscitam questionamentos e indagações sobre o entendimento dos profissionais dessa instituição acerca da importância da história da cultura africana e dos afro-brasileiros, pretendemos contribuir para superar as contradições, favorecendo o debate sobre as relações étnicorraciais e acolhimento real da Lei n. 10.639/2003, apontando caminhos para adesão coletiva da proposta e potencializando descobertas de metodologias para aplicação da lei nas práticas pedagógicas.

Assim, acreditamos que a educação, vista como um caminho próspero para a transformação social, sempre foi sinônimo de lutas da sociedade civil e dos movimentos sociais. 


\section{Encontros e desencontros entre os normativos e os documentos da}

creche

Diante do exposto, seguimos contextualizando a pesquisa no âmbito da instituição analisada, assim como em sua mantenedora: a Prefeitura de Florianópolis. A Creche $^{3}$ analisada localiza-se nas encostas do Maciço do Morro da Cruz, assentamento situado no bairro do José Mendes, próximo à área central da cidade. Ela foi fundada no dia 11 de outubro de 1991 e denominada Creche São Sebastião, sendo inicialmente mantida pela Associação de Moradores do Morro da Queimada.

A partir de 2001, a Creche começou a ser mantida pela Prefeitura de Florianópolis, sob a responsabilidade da Secretaria Municipal de Educação (SME), com recursos humanos, físicos, estruturais e pedagógicos, e passou a ser denominada "Creche Morro da Queimada". Hoje, a instituição atende um total de 94 crianças com idades entre 3 e 5 anos, divididas em 5 grupos, por faixa etária. $\mathrm{O}$ quadro de funcionários conta com cinco professores, dez auxiliares de sala, três professores auxiliares de ensino, uma supervisora escolar, uma diretora e dois auxiliares de sala readaptadas.

A comunidade na qual a creche está inserida - Morro da Queimada - é formada por famílias advindas de diferentes regiões do estado de Santa Catarina e de outros, bem como de municípios

${ }^{3}$ Texto extraído do Projeto Político-Pedagógico da Instituição. 
vizinhos; os migrantes trouxeram consigo suas diferentes histórias de vida e suas etnias, sendo que a maioria é negra. Também a maior parte dessas famílias é desfavorecida nos aspectos de ordem social e econômica, e os pais das crianças que frequentam a Unidade Educativa aqui estudada geralmente possuem pouca escolarização.

Pensando nisso, este texto busca apontar de que forma a Secretaria Municipal de Educação de Florianópolis tem trabalhado com a questão étnico-racial e de que maneira a temática é expressa na política e nos documentos normativos da SME, considerando também como essas diretrizes têm sido interpretadas na creche analisada. Iniciamos, então, pela análise dos documentos produzidos para a rede municipal de ensino, tendo os parâmetros nacionais como âncora.

Os documentos da SME de Florianópolis tiveram seu ápice no triênio 2009-2011, período em que são demarcadas as maiores mudanças de âmbito nacional. A questão racial foi posta em movimento desde 1994, com a elaboração da Lei n. $4.446 / 94^{4}$ pelo vereador Márcio de Souza, que, enquanto pesquisador e militante do movimento negro, atuou em prol da questão racial. No entanto, embora essa lei tenha sido colocada em movimento nesse período, ela não se constituiu.

Anterior às Leis de Diretrizes e Bases - LDB, a referida lei de 1994 dispõe a inclusão do conteúdo "história afro-brasileira" nos currículos das escolas da rede. Assim diz:

\footnotetext{
${ }^{4}$ Lei Municipal no 4446/94 - insere a obrigatoriedade das ações desde a pré-escola, conteúdo "história afro-brasileira" nos currículos das escolas da rede.
} 
Art. $1^{\circ}$ - As escolas da Rede Municipal de Ensino incluirão no programa das disciplinas de Estudos Sociais, História e Geografia o conteúdo "História Afro-Brasileira".

Art. $2^{\circ}$ - A inclusão deste conteúdo será destinada às crianças da pré-escola e de todas as séries do $1^{\circ}$ grau. (FLORIANÓPOLIS, 1994, p. 1).

De acordo com Dias (2011, p. 30) $)^{5}$, a Lei Municipal n. 4.446/94 foi um avanço do ponto de vista das normativas, porém não se constituiu em execução de práticas pedagógicas que contemplassem a educação das relações étnicorraciais. Os movimentos sociais negros sempre tiveram na educação um dos focos de suas reivindicações, demandando melhoras nas condições de ensino da população negra e atendimento em regime de igualdade (CARDOSO, 2008) ${ }^{6}$.

A seguir, elencamos os documentos municipais, buscando investigar de que forma eles apresentam a questão racial. São eles:

- Plano Municipal de Educação de Florianópolis/SC (FLORIANÓPOLIS, 2009c);

- Diretrizes Educacionais Pedagógicas para a Educação Infantil (FLORIANÓPOLIS, 2010);

\footnotetext{
${ }^{5}$ Karina de Araújo Dias (2011).

${ }^{6}$ Paulino de Jesus Francisco Cardoso (2008).
} 
- Orientações Curriculares para Educação Infantil da Rede Municipal de Florianópolis/SC (FLORIANÓPOLIS, 2012);

- Currículo da Educação Infantil da Rede Municipal de Ensino de Florianópolis (FLORIANÓPOLIS, 2015).

O Plano Municipal de Educação de Florianópolis - SC é subdividido em dezesseis eixos temáticos, os quais contêm diretrizes e metas. Na parte introdutória, o documento traz a afirmação de uma sociedade em transformação: "O homem, as instituições, a sociedade, vivem constante e veloz processo de transformação nas relações sociais estabelecidas, alimentando as desigualdades" (FLORIANÓPOLIS, 2009c). Cada um dos nove eixos traz parâmetros para a educação infantil, destacando que o item diversidade aparece atrelado à cultura.

O Eixo Temático "Educação das Relações" se fundamenta em três princípios norteadores:

- A consciência política e histórica da diversidade e pluralidade da sociedade brasileira;

- A exigência do fortalecimento de identidades plurais e a afirmação de direitos, particularmente daqueles 
segmentos historicamente discriminados, como a população afro-brasileira, os povos indígenas e os grupos étnicos minoritários;

- A consecução de ações educativas de promoção de igualdade étnico-racial e de combate ao racismo e a quaisquer formas de discriminação da sociedade multirracial e pluriétnica, justa e equânime.

Em suas metas, o Plano Municipal de Educação, além de reafirmar a importância de se tomar a diversidade como princípio, estabelece e orienta que os Projetos Políticos-Pedagógicos (P. P. P.) apresentem definições, visando ao combate do racismo e das discriminações, com metas para implementar as Diretrizes Nacionais para a Educação das Relações Étnicorraciais.

As Diretrizes Educacionais Pedagógicas para a Educação Infantil (FLORIANÓPOLIS, 2010) apresentam os princípios norteadores do ensino e vinculam o campo cultural à diversidade étnica. Na terceira e última parte do documento, há relatos de vivências de dez unidades de educação infantil de Florianópolis/SC.

Essas diretrizes municipais nos direcionam ao Referencial Curricular Nacional para a Educação Infantil (BRASIL, 1998), que cita um modelo de ação e adesão de projetos educativos voltados para o acolhimento da diversidade. Porém, por se tratar de direcionamentos 
que têm como objetivo estabelecer parâmetros para o sistema educacional, no que se refere à organização e funcionamento das instituições de Educação Infantil, eles demarcam uma ruptura, se pensarmos no princípio dessas propostas: trazer a identidade cultural a partir de projetos desenvolvidos na Rede Municipal de Educação (RME).

As Orientações Curriculares para Educação Infantil da Rede Municipal de Florianópolis/SC (FLORIANÓPOLIS, 2012) foram concebidas de maneira a servir como um guia de cunho educacional para a reflexão sobre os objetivos, os conteúdos e as práticas didáticas dos profissionais que atuam diretamente com crianças de zero a seis anos, respeitando seus estilos pedagógicos e a diversidade cultural brasileira. Esse documento representa um avanço e traz diversidade, gênero, etnia e cultura como princípios constituintes das relações sociais e educativas; as ações pedagógicas, com uma abordagem culturalista da diversidade, são orientadas por um olhar que contempla as crianças como sujeitos múltiplos e diversos.

Por fim, o Currículo da Educação Infantil/PMF (FLORIANÓPOLIS, 2015) também representa um avanço, por se tratar do primeiro currículo da rede de educação infantil estabelecendo aquilo que deve constar nas ações pedagógicas. Esse documento parte do princípio da valorização de diferentes origens culturais, sugerindo a

${ }^{7}$ Prefeitura Municipal de Florianópolis. 
inclusão de histórias, contos e lendas que vão ampliando o repertório das crianças para além da tradição europeia. Ele também sugere a ampliação do acervo bibliográfico da unidade escolar através da pesquisa constante das culturas africanas, indígenas, latino-americanas, orientais, entre outras. Se pensarmos em termos de escrita, ao longo do texto observamos uma continuidade das Orientações Curriculares da PMF (FLORIANÓPOLIS, 2015), percebendo que a abordagem parte do mesmo princípio das Orientações e Ações para a Educação das Relações Étnico-Raciais (BRASIL, 2006).

Diante do exposto, concluímos que os documentos da $\mathrm{SME}^{8}$ de Florianópolis dialogam com os nacionais, seguindo a lógica de suas estruturas, trabalhando a diversidade de forma mais detalhada, além das relações étnicorraciais, e trazendo a construção de identidades, do respeito, da valorização e do reconhecimento como elementos imprescindíveis a serem considerados. Constatamos que a inserção da diversidade nos documentos é considerada uma das políticas educacionais propostas pela SME.

Cabe-nos destacar que nos textos apresentados pela SME a questão racial não está silenciada, embora ainda encontrássemos lacunas entre uma normativa e outra. Porém, por valorizar a diversidade como caminho próspero para combater o racismo, e o enfrentamento de questões como o mito da democracia racial, que há muito tempo tenta

${ }^{8}$ Secretaria Municipal de Educação de Florianópolis. 
imprimir uma falsa igualdade entre brancos e negros, esses documentos contribuem para o não silenciamento de tais questões.

Atribuímos essas modificações à atuação e participação de militantes do movimento negro e pesquisadores/as da área que, através de lutas, debates, embates e proposições, principalmente no âmbito educacional, vêm conquistando mudanças na ação do poder público (RODRIGUES, 2011, p. 12).

No entanto, existe ao longo do processo uma distância entre as leis e a sua aplicação, que é limitada por uma forte relutância, por silenciamentos, tensões e resistências balizadas pela etiqueta das relações raciais e da cordialidade que, a partir de um discurso universalista, se utiliza do silêncio como estratégia comumente adotada. Assim, concordamos com Munanga (2001, p. 32) quando ele diz que "qualquer proposta de mudança em benefício dos excluídos jamais receberia um apoio unânime, sobretudo quando se trata de uma sociedade racista".

Resta-nos, nesse momento, continuar indagando sobre a forma como as políticas propostas pelos documentos municipais estão sendo traduzidas e interpretadas pela Creche Morro da Queimada. É importante ressaltar que a presente pesquisa tem uma característica singular, por emergir da aproximação da pesquisadora com o Núcleo de Estudos Afro-Brasileiros (NEAB) da Universidade do Estado de Santa Catarina (UDESC). Posteriormente, houve a inclusão da instituição 
investigada no projeto "Suporte às Políticas Públicas de Implementação da Lei 10.639/03 em Santa Catarina"9, vinculado ao Programa Memorial Antonieta de Barros, do NEAB/UDESC. Esse projeto objetiva oferecer suporte técnico e pedagógico aos/às gestores/as públicos/as responsáveis pela implementação da Lei Federal n. 10.639/03 em âmbito local, estadual e regional.

Desse modo, a finalidade do projeto de extensão está relacionada tanto ao suporte às instituições e educadores(as) quanto à contribuição na formação continuada dos profissionais de educação, apoiando-os e criando condições que proporcionem debates acerca das desigualdades raciais e das formas de implementação das leis e diretrizes. Visa-se também procurar maneiras de efetivar essas políticas na escola e articulá-las com os conteúdos lecionados pelo(a) educador(a), chegando à ponta do sistema - o chão da escola -, no que diz respeito à inserção da educação das relações étnicorraciais nos currículos e práticas escolares, como respaldado pela Lei Federal n. $10.639 / 03$.

Falando em "chão da escola", partem daí nossas primeiras indagações para alcançar os objetivos que nasceram da observação participante, necessitando sensibilizar nosso olhar para a compreensão do espaço e significados postos no ambiente. Por isso, foi necessário ampliar a atenção sobre o que parecia estar evidente e buscar uma

\footnotetext{
${ }^{9}$ Fonte: PROEXT (2013).
} 
observação atenta e cuidadosa, mobilizando nossos conhecimentos com elementos ínfimos, com os quais estamos envolvidos (GRAUE; WALSH, 2003, p. 118).

Buscou-se aguçar o olhar para os diferentes ângulos a serem conhecidos dentro um mesmo local, já que cada olhar nos fornecia dados essenciais para a construção da descrição da realidade a ser conhecida; o trabalho de observação possibilitou uma maior interação com o campo e com a comunidade escolar. Segundo Geertz (1989), os estudos etnográficos exigem um esforço de "interpretação" e, como salienta o autor, "fazer etnografia é como tentar ler um manuscrito estranho, desbotado, cheio de elipses, incoerências, emendas suspeitas e comentários tendenciosos" (GEERTZ, 1989, p. 20).

O documento que sistematiza as propostas e concepções das unidades educativas da Prefeitura Municipal de Florianópolis é orientado com base na Resolução n. 03/2009 ${ }^{10}$ (FLORIANÓPOLIS, 2009b) e na Resolução n. 01/2009 do Conselho Municipal de Educação (FLORIANÓPOLIS, 2009a), que fixam normas para a Educação Infantil no âmbito do Sistema Municipal de Ensino do Município de Florianópolis/SC. Ao analisar o texto, fica explícito que a creche aqui analisada se trata de uma unidade escolar que tem clareza da multiplicidade de indivíduos que abriga. "Aqui dividem o espaço"

\footnotetext{
${ }^{10}$ Resolução 003/2009 do Conselho Municipal de Educação: Fixa normas para a elaboração do Projeto Político Pedagógico e Regimento das Instituições de Educação integrantes do Sistema Municipal de Ensino do Município de Florianópolis.
} 
negros, brancos, pardos, evangélicos, espíritas, católicos, umbandistas, dentre outros, demonstrando a riqueza de experiências manifestas nesse meio. As diferenças referentes a cor, raça, etnia e credo abrem a creche para um espaço de crítica e diversidade, elementos que constituem crescimento e cidadania.

No entanto, o documento não apresenta dados da origem das famílias da comunidade escolar ou como elas se autodeclaram, assim como não fundamenta nem utiliza aportes teóricos sobre como aborda e trabalha com a diversidade. Infelizmente, também não contempla uma educação voltada para a luta antirracista, embora palavras como diversidade, identidade, religiosidade sejam citadas ao longo do documento. Assim, interpretamos esses termos como palavras-padrão para a produção de um discurso universal, visto que os documentos normativos nacionais não aparecem ao longo do texto.

Assim como nos fundamentos norteadores, a adesão de projetos coletivos, como o "Projeto Étnico Racial", surge numa tentativa de visibilizar a questão, porém não traz nenhum possível princípio para concretizá-la na prática, revelando um silêncio que envolve a questão racial de trabalhos que consideram a creche e relações raciais. Na proposta pedagógica inexistem metas e ações como prioridades, visto que no diagnóstico escolar não se explicita que as relações entre crianças negras e brancas na educação infantil possivelmente são e serão marcadas por conflitos, balizadas por 
preconceitos e estereótipos, inferiorizando determinadas culturas em relação às outras. Da mesma forma, o documento não utiliza dados empíricos para caracterizar a comunidade atendida, não apresentando articulação entre os Estudos Sociais da Infância e os Estudos sobre Relações Étnicorraciais no Brasil.

Nesse modelo de elaboração do P. P. P., deparamo-nos com contradições que mostram que a discussão sobre a Lei n. 10.639 não está posta. A própria concepção de educação infantil abordada no projeto da escola por si só traz a compreensão e o reconhecimento da infância e da criança, mas ao longo do documento não percebemos essas singularidades expressas nem referenciadas na sua estruturação. Os conceitos estão dispostos de uma forma muito ampla, não apontando caminho para trabalhar e incluir a Lei n. 10.639 como uma ação pedagógica dentro da instituição.

A partir daí, encontramos um dos primeiros entraves: como implementar algo que não é visibilizado nos documentos oficiais presentes na instituição? O mesmo se percebe no Plano de Gestão, em que "o documento explicita um discurso universal desconsiderando os aspectos de raça, etnia, classe social e gênero". O discurso da gestão democrática aparece ao longo do documento, porém oculta o papel do gestor como um dos protagonistas e executores das políticas públicas do Estado. Esse documento demonstra uma ausência no que tange às questões sobre a diversidade e a consciência clara da nova perspectiva 
de ressignificação do papel da gestão diante dos novos paradigmas. No Plano de Metas Anual inexiste qualquer ação voltada para a superação das desigualdades dentro da unidade educativa, não contemplando uma educação voltada para a luta antirracista e revelando um silêncio em relação à questão racial.

Seguindo na investigação, a partir de relatos informais ocorridos por meio de diálogos com os professores/as, com a gestora e a supervisora da instituição estudada, complementamos os dados e as observações realizadas durante a pesquisa. A partir dos relatos das/os profissionais percebemos que o desejo de implementar a Lei Federal 10.639/03 não vem sendo silenciado e, muito pelo contrário, vem borbulhando nos encontros e diálogos informais.

Todavia, a busca até então foi por propostas prontas que não estavam articuladas com as reflexões pautadas nos documentos norteadores e, na maioria das situações, com reflexões sem objetivos claros de onde se almejava chegar. Analisando a formação continuada disponibilizada pelo município de Florianópolis/SC, foi possível constatar que a capacitação complementar voltada para a questão das relações étnicorraciais na PMF ocorre na modalidade de formação em serviço, em encontros gerais, por meio de seminários, palestras e cursos. Embora a formação docente para as questões raciais tenha se intensificado na SME no ano de 2009, muitos profissionais não foram 
contemplados com isso, pois em alguns momentos esse processo se concretiza através de representatividade.

De acordo com Silva (2010), o uso do recurso de professores/as multiplicadores/as levanta algumas implicações, principalmente a respeito das dificuldades de socialização das discussões, problematizações e materiais dispostos durante o curso para os/as demais integrantes das unidades. Esse cenário vem ao encontro dos resultados de pesquisas (DIAS, 2011; SILVA, 2010) que apontam que, embora existam propostas que busquem contemplar a temática, as ações são proporcionalmente pequenas, considerando a gama total de formações e demais atuações que são promovidas pelas Secretarias de Educação. Por isso a relevância da inclusão de todos os sujeitos nos ambientes de formação.

Nas falas dos profissionais, a modalidade de formação em serviço é a que tem mais contribuído para as suas práticas pedagógicas, pois abrange todos os profissionais, propiciando debates que vão ao encontro das necessidades cotidianas e acontecimentos vividos. Quando questionados sobre como lidam com as questões de racismo no cotidiano, as respostas dos profissionais de educação muitas vezes são permeadas pelo mito da igualdade racial. Com isso, muitas/os professoras/es silenciam e reproduzem ações de preconceito racial, reforçando desigualdades. 
A resultante da nossa pesquisa aponta para a necessidade de uma reestruturação dos moldes atuais da visão de educação da grande maioria dos profissionais. Nesse sentido, a investigação que está sendo desenvolvida na Creche Morro da Queimada segue apontando novos caminhos.

\section{Referências}

BRASIL. Ministério da Educação. Diretrizes Curriculares Nacionais para a Educação das Relações Étnico-raciais e para o Ensino de História e Cultura Afro Brasileira e Africana. Brasília: MEC, 2005.

. Educação Infantil: bibliografia anotada. Brasília: MEC, 1995.

. Lei de Diretrizes e Bases da Educação Nacional. Brasília: MEC, 1996.

. Orientações e ações para a educação das relações étnicoraciais. Brasília: SECAD, 2006.

Referencial Curricular Nacional para a Educação Infantil: Introdução, v. 1. Brasília: MEC, 1998.

CARDOSO, Paulino de Jesus Francisco. Notas sobre o movimento negro no Brasil. In: SPONCHIADO, Inês Justina; SILVA, Vania Beatriz Monteiro (Org.). Contribuições para a Educação das Relações Étnico-Raciais. Florianópolis: Letras Contemporâneas, 2008.

DIAS, Karina Araújo. Formação Continuada para Diversidade Étnico-Racial: Desafios Pedagógicos no Campo das Ações Afirmativas na Rede Municipal de Ensino de Florianópolis. 2011. 285 f. Dissertação (Mestrado em Educação) - Universidade Federal de Santa Catarina, Florianópolis, 2011. 
FLORIANÓPOLIS. Câmara Municipal de Vereadores. Lei n. 4.446 de 05 de julho de 1994. Florianópolis, 1994.

FLORIANÓPOLIS. Prefeitura Municipal. Conselho Municipal de Educação. Resolução n. 01/2009. Florianópolis: SME, 2009a.

. Resolução n. 03/2009. Florianópolis: SME, 2009b.

Plano Municipal de Educação de Florianópolis. Florianópolis: SME, 2009c.

. Orientações Curriculares para Educação Infantil da Rede Municipal de Florianópolis/SC. Florianópolis: SME, 2012.

FLORIANÓPOLIS. Prefeitura Municipal. Secretaria Municipal de Educação. Diretrizes educacionais pedagógicas para educação infantil. Florianópolis: Prelo, 2010.

. Currículo da Educação Infantil da Rede Municipal de Ensino de Florianópolis. Florianópolis: SME, 2015.

GEERTZ, Clifford. A interpretação das culturas. Rio de Janeiro: Zahar, 1989.

GRAUE, M. Elizabeth; WALSH, Daniel J. Investigação etnográfica com crianças: teorias, métodos e ética. Lisboa: Fundação Calouste Gulbenkian, 2003.

MUNANGA, Kabengele. Políticas de ação afirmativa em benefício da população negra no Brasil: um ponto de vista em defesa de cotas. Revista Sociedade e Cultura, v. 4, n. 2, p. 31-43, jul./dez. 2001.

RODRIGUES, Tatiane Consentino. A ascensão da diversidade nas políticas educacionais contemporâneas. 2011. $234 \mathrm{f}$. Tese (Doutorado em Educação) - Universidade Federal de São Carlos, São Carlos, 2011.

SILVA, Kátia Vicente da. A Implementação da Lei $10.639 / 03$ no Município de São João de Meriti: Limites e Possibilidades. 2010. 114 105

Revista Vernáculo n. ${ }^{\circ} 39$ - primeiro semestre /2017 
f. Dissertação (Mestrado em Educação) - Universidade Federal do Estado do Rio de Janeiro, Rio de Janeiro, 2010.

Recebido em 31/10/2015, aceito para publicação em 27/09/2016 